ARTICLE

\title{
A porous metal-organic framework with ultrahigh acetylene uptake capacity under ambient conditions
}

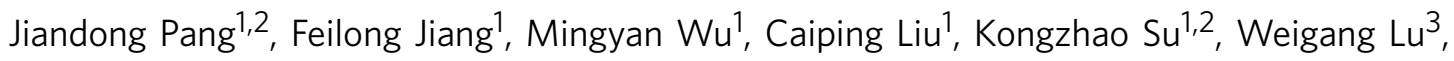

Daqiang Yuan ${ }^{1} \&$ Maochun Hong ${ }^{1}$

Acetylene, an important petrochemical raw material, is very difficult to store safely under compression because of its highly explosive nature. Here we present a porous metal-organic framework named FJ-H8, with both suitable pore space and rich open metal sites, for efficient storage of acetylene under ambient conditions. Compared with existing reports, FJI-H8 shows a record-high gravimetric acetylene uptake of $224 \mathrm{~cm}^{3}$ (STP) $\mathrm{g}^{-1}$ and the second-highest volumetric uptake of $196 \mathrm{~cm}^{3}$ (STP) $\mathrm{cm}^{-3}$ at $295 \mathrm{~K}$ and $1 \mathrm{~atm}$. Increasing the storage temperature to $308 \mathrm{~K}$ has only a small effect on its acetylene storage capacity $\left(\sim 200 \mathrm{~cm}^{3}\right.$ (STP) $\mathrm{g}^{-1}$ ). Furthermore, FJI-H8 exhibits an excellent repeatability with only $3.8 \%$ loss of its acetylene storage capacity after five cycles of adsorption-desorption tests. Grand canonical Monte Carlo simulation reveals that not only open metal sites but also the suitable pore space and geometry play key roles in its remarkable acetylene uptake.

\footnotetext{
${ }^{1}$ State Key Laboratory of Structure Chemistry, Fujian Institute of Research on the Structure of Matter, Chinese Academy of Sciences, Fuzhou, Fujian 350002 China. ${ }^{2}$ University of Chinese Academy of Sciences, Beijing 100049, China. ${ }^{3}$ Department of Chemistry, Texas A\&M University, College Station, Texas 77843 , USA. Correspondence and requests for materials should be addressed to M.W. (email: wumy@fjirsm.ac.cn) or to D.Y. (email: ydq@fjirsm.ac.cn).
} 
A cetylene is a very important chemical feedstock for modern industry ${ }^{1,2}$. Many widely used polymer products such as polyurethane and polyester plastics are synthesized from acetylene. However, the safe storage and transportation of acetylene still remain challenging because of its explosiveness when compressed under pressures over $2 \mathrm{~atm}$ at room temperature ${ }^{3,4}$. Therefore, acetylene gas extensively used in industry so far has to be stored in special cylinders filled with acetone and porous materials suffering from lower acetylene purity and higher storage cost. Fortunately, the emergence of porous metal-organic frameworks (MOFs) brings promising solutions to the above problem due to their excellent performance for storage and separation of gases such as $\mathrm{H}_{2}, \mathrm{O}_{2}$, $\mathrm{CH}_{4}$ and $\mathrm{CO}_{2}$ (refs 5-17). MOFs have been recently studied for acetylene storage application ${ }^{18-27}$. For example, at $273 \mathrm{~K}$ ZJU-5 shows a high acetylene uptake of $290 \mathrm{~cm}^{3}$ (STP) $\mathrm{g}^{-1}$. However, the uptake drastically decreases to $193 \mathrm{~cm}^{3}$ (STP) $\mathrm{g}^{-1}$ when the temperature rises to $295 \mathrm{~K}^{18}$. To effectively improve acetylene storage capacity at room temperature, Chen et al. explored a series of microporous MOFs with different structures and porosities and concluded that open $\mathrm{Cu}(\mathrm{II})$ sites and suitable pore space in MOFs played crucial roles for acetylene storage ${ }^{18-22}$. In addition, the dendritic multi-carboxylate ligands with $m$-benzenedicarboxylate moieties tend to form various polyhedral nanocages along with rich open $\mathrm{Cu}(\mathrm{II})$ sites, which has been demonstrated as an efficient approach to improve the gas uptakes ${ }^{26-33}$.

Considering the previous studies, we designed and synthesized a new robust multi-carboxylate ligand $3,3^{\prime}, 5,5^{\prime}$-tetra $(3,5-$ dicarboxyphenyl)-4,4'-dimethoxy-biphenyl $\left(\mathrm{H}_{8} \mathrm{tddb}\right.$, Supplementary Fig. 1). Reaction of $\mathrm{H}_{8} \mathrm{tddb}$ and $\mathrm{Cu}\left(\mathrm{NO}_{3}\right)_{2}$ under solvothermal conditions resulted in a porous MOF $\left(\left[\mathrm{Cu}_{4}(\mathrm{tddb}) \cdot\left(\mathrm{H}_{2} \mathrm{O}\right)_{4}\right]_{n}\right.$. (solvent $)_{x}$, abbreviated as FJI-H8) with both suitable pore space and open metal sites. At $295 \mathrm{~K}$, FJI-H8 exhibits a record-high acetylene uptake of $224 \mathrm{~cm}^{3}$ (STP) $\mathrm{g}^{-1}$, greatly exceeding the previous record of $201 \mathrm{~cm}^{3}$ (STP) $\mathrm{g}^{-1}$ held by HKUST-1 (ref. 19). Increasing the storage temperature to $308 \mathrm{~K}$ has only small effect on its acetylene storage capacity $\left(\sim 200 \mathrm{~cm}^{3}\right.$ (STP) $\mathrm{g}^{-1}$ ). Furthermore, the acetylene adsorption amount of FJI-H8 at $295 \mathrm{~K}$ has no obvious loss after five cycles of adsorption-desorption test.

\section{Results}

Structure of FJI-H8. Single-crystal X-ray diffraction experiments revealed that FJI-H8 crystallized in the tetragonal space group $\mathrm{PH}_{2} / \mathrm{nnm}$ (Supplementary Data 1 ). In the asymmetric unit, there are one-quarter of organic ligand and two kinds of $\mathrm{Cu}(\mathrm{II})$ ions both with the occupancies of $50 \%$. One metal site is located on a mirror plane, while the other resides on a twofold axis. Further, the dinuclear core is centred about an inversion site. All the eight carboxyl groups are deprotonated in the organic ligand. Two inner phenyl rings of tddb are coplanar, while the four outer isophthalate groups are almost perpendicular to the diphenyl with a dihedral angle of $78.85^{\circ}$ (Supplementary Fig. 2). Each tddb ligand coordinates to eight dicopper(II) paddlewheel secondary building units (SBUs) and each $\mathrm{Cu}_{2}$ SBU links to four tddb ligands. As anticipated, there are three types of polyhedral nanocages in FJI-H8 (Supplementary Fig. 3), that is, one regular cuboctahedron (Cage-A), one distorted octahedron (Cage-B) and one distorted cuboctahedron (Cage-C) (Fig. 1a). Cage-A is constructed by eight $\mathrm{Cu}_{2}$ SBUs and four tddb ligands. The centres of the eight paddlewheels together with the centroids of the four tddb ligands are considered as the 12 four-connected vertices of the cage. Therefore, the pore diameter is around $15 \AA$, which is estimated through the separations of two opposite vertexes.
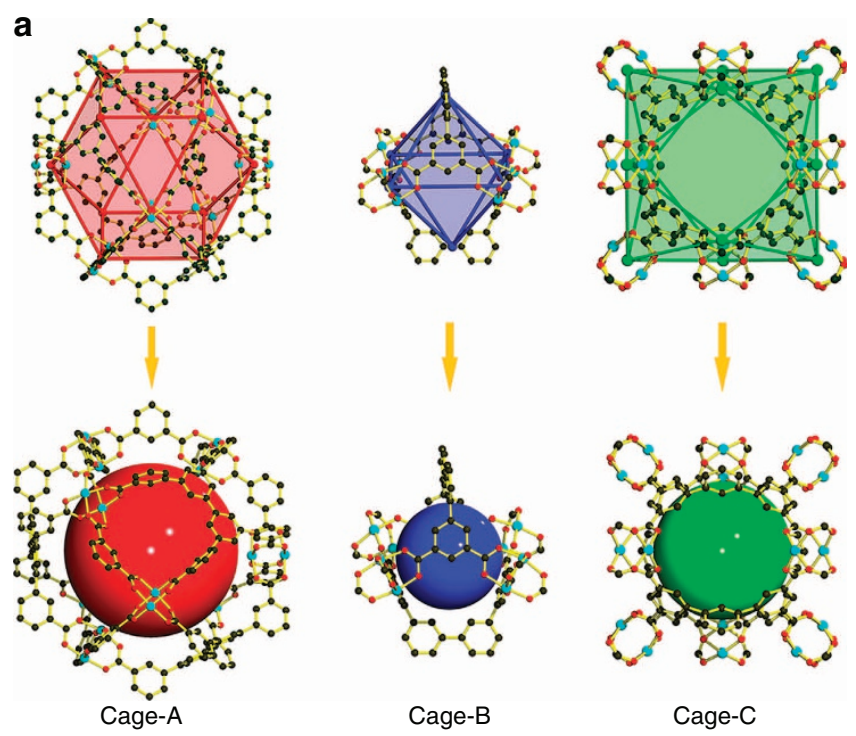

b
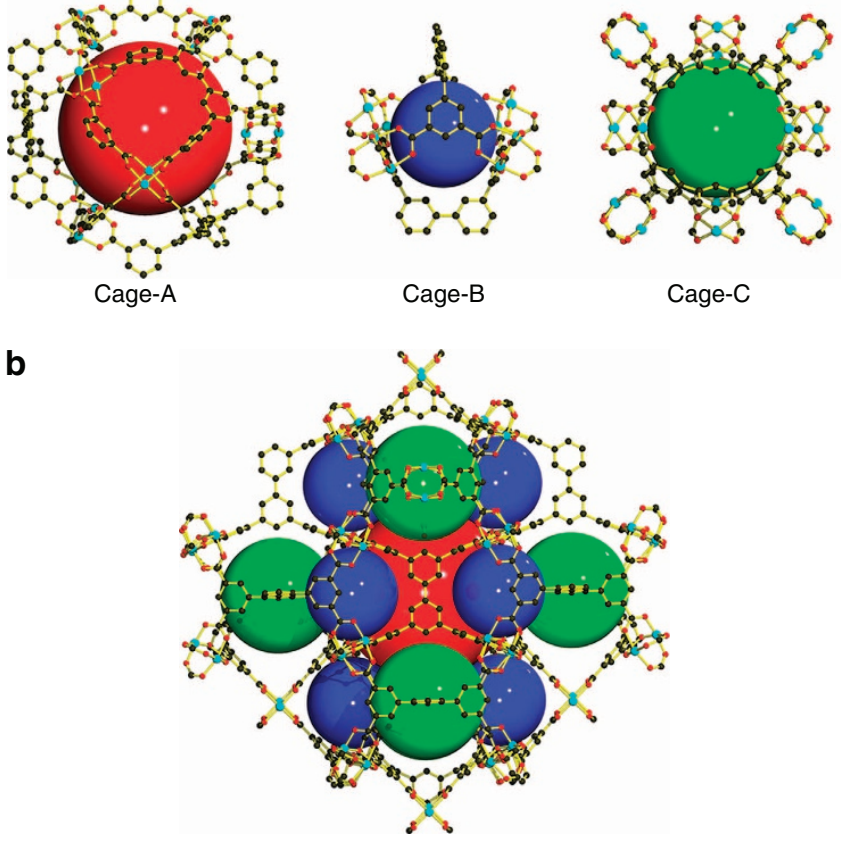

Figure 1 | Structural representations of FJI-H8 from X-ray diffraction data. (a) Three types of polyhedral nanocages observed in $\mathbf{F J I - H 8}$, that is, one regular cuboctahedral cage (Cage-A), one distorted octahedral cage (Cage-B) and one distorted cuboctahedral cage (Cage-C). (b) Combination of the three types of polyhedral nanocages. (The hydrogen atoms and hydroxymethyl groups are omitted for clarity.)

In addition, eight open $\mathrm{Cu}(\mathrm{II})$ sites point towards the centre of the cage and can interact directly with gas molecules residing inside, which can improve the gas adsorption ability ${ }^{34-38}$. Cage- $B$ consists of four $\mathrm{Cu}_{2}$ SBUs and two halves of tddb ligands, with a dimension of $\sim 8 \AA$. For Cage- $\mathrm{C}$, its 12 vertices consist of the centroids of eight $\mathrm{Cu}_{2}$ SBUs and four halves of tddb ligands, respectively. In addition, the dimension of this cage is estimated to be around $12 \AA$. On the whole, Cage- $\mathrm{A}$ is linked by six Cage- $\mathrm{C}$ through six rhombic faces and eight Cage- $B$ through eight triangular faces (Supplementary Fig. 4). Similarly, Cage-C is linked by six Cage-A through six rhombic faces and eight Cage- $\mathrm{B}$ by sharing eight $m$-benzenedicarboxylate moieties (Supplementary Fig. 5). However, Cage-B is linked by four Cage-A through four triangular faces and four Cage- $\mathrm{C}$ by sharing four $m$-benzenedicarboxylate moieties (Supplementary Fig. 6). It should be noted that there are two kinds of $\mathrm{Cu}_{2}$ SBUs in FJI-H8 due to the fact that the distance between the paddlewheels and the centroids of the ligands are slightly different (8.96 and $9.45 \AA$, respectively). For the sake of clarity, if we simplify two types of $\mathrm{Cu}_{2}$ SBUs as two kinds of four-connected nodes and the tddb ligands as eight-connected nodes, FJI-H8 adopts the rare $(4,4,8)$-c URJ network with the topological point symbol of $4^{14} \cdot 6^{12} \cdot 8^{2}$ (Supplementary Fig. 7) ${ }^{39}$. 
Porosity and $\mathbf{N}_{2}$ adsorption of FJI-H8. The solvent accessible volume in fully evacuated FJI-H8 is $62.4 \%$ calculated by PLATON with a probe of $1.8 \AA$ (ref. 40). To check the permanent porosity of FJI-H8, nitrogen adsorption isotherm was measured at $77 \mathrm{~K}$ and $1 \mathrm{~atm}$. As demonstrated by powder X-ray diffraction (PXRD, Supplementary Fig. 8), the activated sample retained the crystallinity after being evacuated for $10 \mathrm{~h}$ under $80^{\circ} \mathrm{C}$. The $\mathrm{N}_{2}$ sorption of FJI-H8 exhibits a typical reversible type I isotherm with a saturated adsorption amount of $531 \mathrm{~cm}^{3}$ (STP) $\mathrm{g}^{-1}$, indicating the microporous nature of FJI-H8. The BrunauerEmmett-Teller apparent surface area calculated from the $\mathrm{N}_{2}$ adsorption data is $2025 \pm 15 \mathrm{~m}^{2} \mathrm{~g}^{-1}$ and is well consistent with theoretical one $\left(1907 \mathrm{~m}^{2} \mathrm{~g}^{-1}\right)$ calculated by Poreblazer ${ }^{41}$, which demonstrates that the sample is fully activated. Accordingly, the total pore volume is $0.82 \mathrm{~cm}^{3} \mathrm{~g}^{-1}$. From the $\mathrm{N}_{2}$ adsorption data, analysis by the non-local density functional theory (NLDFT) model confirms a narrow distribution of micropores around $12 \AA$ (Fig. 2).

Acetylene adsorption property of FJI-H8. Considering the open metal sites and moderate pores in FJI-H8, its low-pressure acetylene uptake was measured under $1 \mathrm{~atm}$. As expected, the $\mathrm{C}_{2} \mathrm{H}_{2}$ adsorption amount for FJI-H8 reaches up to $277 \mathrm{~cm}^{3}$ (STP) $\mathrm{g}^{-1}$ at $273 \mathrm{~K}$ and $1 \mathrm{~atm}$, slightly less than the record of $290 \mathrm{~cm}^{3}$ (STP) $\mathrm{g}^{-1}$ (ref. 18). In practice, $\mathrm{C}_{2} \mathrm{H}_{2}$ gas is stored at ambient temperatures. Therefore, the $\mathrm{C}_{2} \mathrm{H}_{2}$ adsorption experiment at room temperature $(295 \mathrm{~K})$ was carried out. Exhilaratingly, FJI-H8 exhibits an adsorption amount of $224 \mathrm{~cm}^{3}$ (STP) $\mathrm{g}^{-1}$ for acetylene at $295 \mathrm{~K}$ and $1 \mathrm{~atm}$, which is greatly higher than those of the two famous MOFs, known as HKUST-1 $\left(201 \mathrm{~cm}^{3}\right.$ (STP) $\left.\mathrm{g}^{-1}\right)$ and CoMOF-74 $\left(197 \mathrm{~cm}^{3}\right.$ (STP) $\mathrm{g}^{-1}$ ) (Table 1). Surprisingly, FJI-H8 exhibits an acetylene uptake of $206 \mathrm{~cm}^{3}$ (STP) $\mathrm{g}^{-1}$ at $303 \mathrm{~K}$ and $1 \mathrm{~atm}$, which prompts us to investigate its acetylene uptake at an even higher temperature. The most commendable aspect is that the acetylene adsorption amount of FJI-H8 still reached $200 \mathrm{~cm}^{3}$ (STP) $\mathrm{g}^{-1}$ even when the temperature increased to $308 \mathrm{~K}$ (Fig. 3a). This value is comparable to that of HKUST- 1 at $295 \mathrm{~K}$. In other words, the acetylene uptake capacity of FJI-H8 decreases by a rate of $2.2 \mathrm{~cm}^{3} \mathrm{~g}^{-1} \mathrm{~K}^{-1}$ with the experimental temperature increasing from 273 to $308 \mathrm{~K}$, which is almost only half to that of ZJU-5 $\left(3.9 \mathrm{~cm}^{3} \mathrm{~g}^{-1} \mathrm{~K}^{-1}\right.$ ) from $273 \mathrm{~K}$ to $298 \mathrm{~K}$ (Supplementary Table 1). Therefore, FJI-H8 is more suitable for practical applications over a wide temperature range around room temperature. In consideration of its practical application, we also tested the repeatability of FJI-H8 for acetylene storage. About $100 \mathrm{mg}$ of

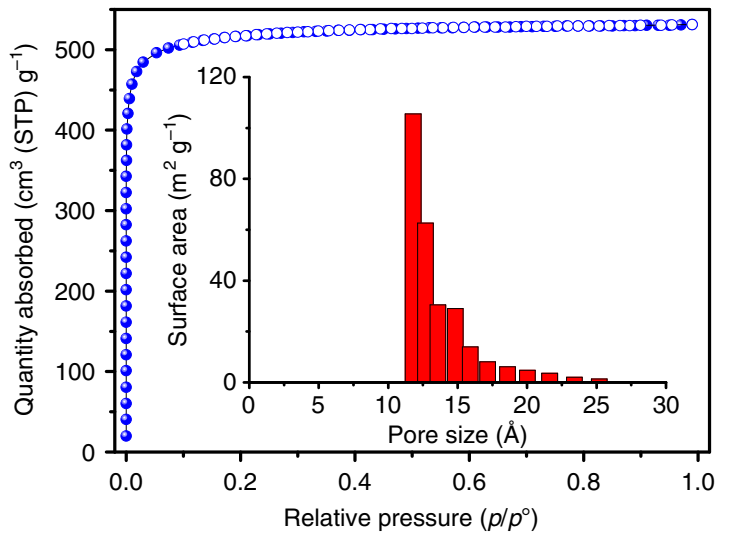

Figure 2 | $\mathbf{N}_{\mathbf{2}}$ sorption data for $\mathbf{F J I - H 8 . ~} \mathrm{N}_{2}$ sorption isotherm at $77 \mathrm{~K}$ (filled symbols: adsorption; open symbols: desorption); inset: pore size distribution analysed by NLDFT method. desolvated sample was loaded onto an ASAP2020-M analyser and five cycles of acetylene adsorption at $295 \mathrm{~K}$ were recorded without the reactivation process between each cycle. For FJI-H8, there is only a $3.8 \%$ loss in absorbed quantity of $\mathrm{C}_{2} \mathrm{H}_{2}$ after five cycles, which indicates that FJI-H8 is promising in refillable acetylene storage (Fig. 3b) ${ }^{42}$.

The isosteric heat of acetylene adsorption for FJI-H8 is calculated to be $32.0 \mathrm{~kJ} \mathrm{~mol}^{-1}$ based on the $\mathrm{C}_{2} \mathrm{H}_{2}$ adsorption isotherms at 273, 295, 303 and $308 \mathrm{~K}$ (Supplementary Fig. 9). This value is larger than that of HKUST-1 $\left(30.4 \mathrm{~kJ} \mathrm{~mol}^{-1}\right)$. As has been reported previously, the high density of open metal sites within MOF materials may play crucial roles in the high acetylene storage capacities and high adsorption enthalpies. Supposing each open metal site binds one acetylene molecule, as established by Chen et al., the acetylene uptake by open $\mathrm{Cu}(\mathrm{II})$ sites in HKUST-1 accounts for c.a. $60 \%$ of the total acetylene uptake at room temperature. For CoMOF-74, almost $80 \%$ of the total acetylene uptake is contributed by open $\mathrm{Co}(\mathrm{II})$ sites assuming each $\mathrm{Co}(\mathrm{II})$ site binds one acetylene molecule. Moreover, for MgMOF-74, if all the open $\operatorname{Mg}(\mathrm{II})$ sites can be fully loaded with one acetylene molecule per one open $\mathrm{Mg}(\mathrm{II})$ site, the theoretical acetylene uptake by open metal sites is even larger than the experimentally measured value at room temperature. As listed in Table 1, for most MOF materials, acetylene uptakes by open metal sites account for almost half of the acetylene uptake or even higher. However, in FJI-H8, the open $\mathrm{Cu}(\mathrm{II})$ site density is $3.59 \mathrm{mmol} \mathrm{g}^{-1}$, which is lower than those for the reported MOFs with high acetylene uptake capacities. On the whole, the open $\mathrm{Cu}$ (II) sites can only contribute $87 \mathrm{~cm}^{3}$ of the total $224 \mathrm{~cm}^{3}$ for the acetylene storage capacity at $295 \mathrm{~K}$ and $1 \mathrm{~atm}$. Thus, the remaining acetylene storage capacity should come from the suitable pore space in FJI-H8. It should be noted that the acetylene uptake by the pore space accounts for $>60 \%$ of the whole acetylene uptake in FJI-H8, which is rarely seen in other reported MOFs. More surprisingly, the whole acetylene uptake decreases to $200 \mathrm{~cm}^{3}$ (STP) $\mathrm{g}^{-1}$ with a slight loss of $24 \mathrm{~cm}^{3}$ (STP) $\mathrm{g}^{-1}$, when the temperature rises from 295 to $308 \mathrm{~K}$. The above result indicates relatively strong interactions between acetylene molecules and pore space in FJI-H8.

In general, there are two kinds of representations to measure the gas adsorption properties of adsorbent materials, that is, gravimetric capacity in the unit of $\mathrm{cm}^{3}(\mathrm{STP}) \mathrm{g}^{-1}$ and volumetric

Table 1 | Contributions of open metal sites (OMSs) and pore space in acetylene uptakes for selected MOFs at room temperature and $1 \mathrm{~atm}$ for gravimetric capacity in the unit of $\mathrm{cm}^{3}$ (STP) $\mathrm{g}^{-1 \star}$.

\begin{tabular}{|c|c|c|c|c|}
\hline \multirow[t]{2}{*}{ Material } & \multirow{2}{*}{$\begin{array}{l}\text { OMS density } \\
\left(\mathbf{m m o l ~ g}^{-1}\right)\end{array}$} & \multicolumn{3}{|c|}{$\mathrm{C}_{2} \mathrm{H}_{2}$ uptake $\left(\mathrm{cm}^{3}(\mathrm{STP}) \mathrm{g}^{-1}\right)$} \\
\hline & & By OMS & By pore space & Sum \\
\hline FJI-H8 & 3.59 & 87 & 137 & 224 \\
\hline FJI-H8 & 3.59 & 87 & 113 & 200 \\
\hline HKUST-1 (ref. 19) & 4.96 & 120 & 81 & 201 \\
\hline CoMOF-74 (ref. 20) & 6.41 & 155 & 42 & 197 \\
\hline ZJU-5 (ref. 18) & 3.87 & 95 & 98 & 193 \\
\hline MgMOF-74 (ref. 20) & 8.24 & $199 \ddagger$ & - & 184 \\
\hline NOTT-101 (ref. 55) & 3.44 & 84 & 100 & 184 \\
\hline ZJU-7 (ref. 56) & 3.46 & 85 & 95 & 180 \\
\hline Cu-TDPAT (ref. 26) & 3.74 & 91 & 87 & 178 \\
\hline PCN-16 (ref. 55) & 4.19 & 102 & 74 & 176 \\
\hline
\end{tabular}



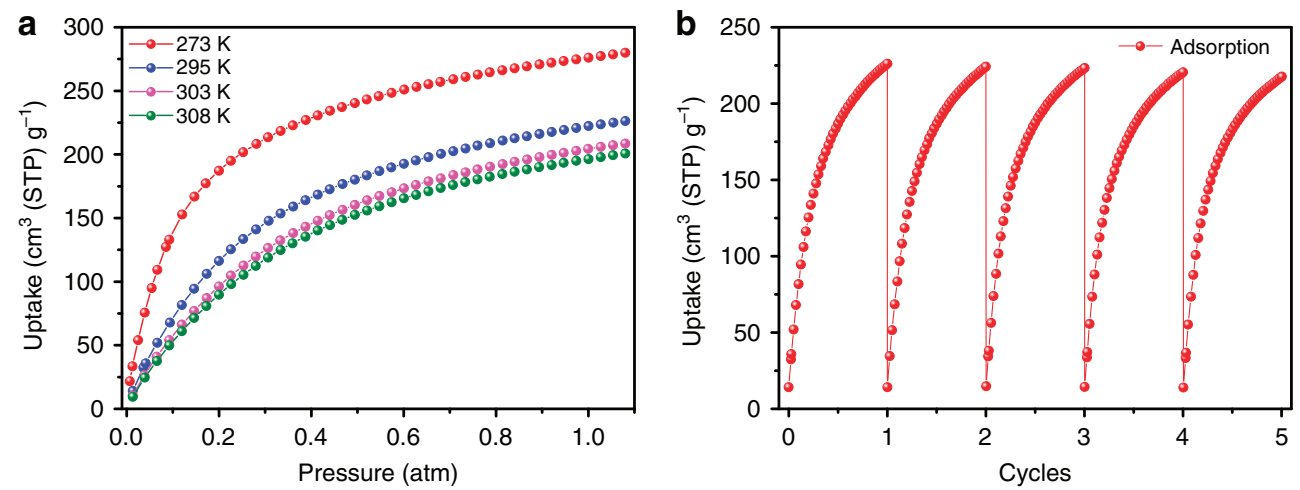

Figure 3 / $\mathbf{C}_{\mathbf{2}} \mathbf{H}_{\mathbf{2}}$ adsorption properties. (a) $\mathrm{C}_{2} \mathrm{H}_{2}$ adsorption isotherms of $\mathbf{F J I - H 8}$ at $273,295,303$ and $308 \mathrm{~K}$. (b) $\mathrm{Cycles}_{\text {of }} \mathrm{C}_{2} \mathrm{H}_{2}$ adsorption for FJI-H8 at $295 \mathrm{~K}$.

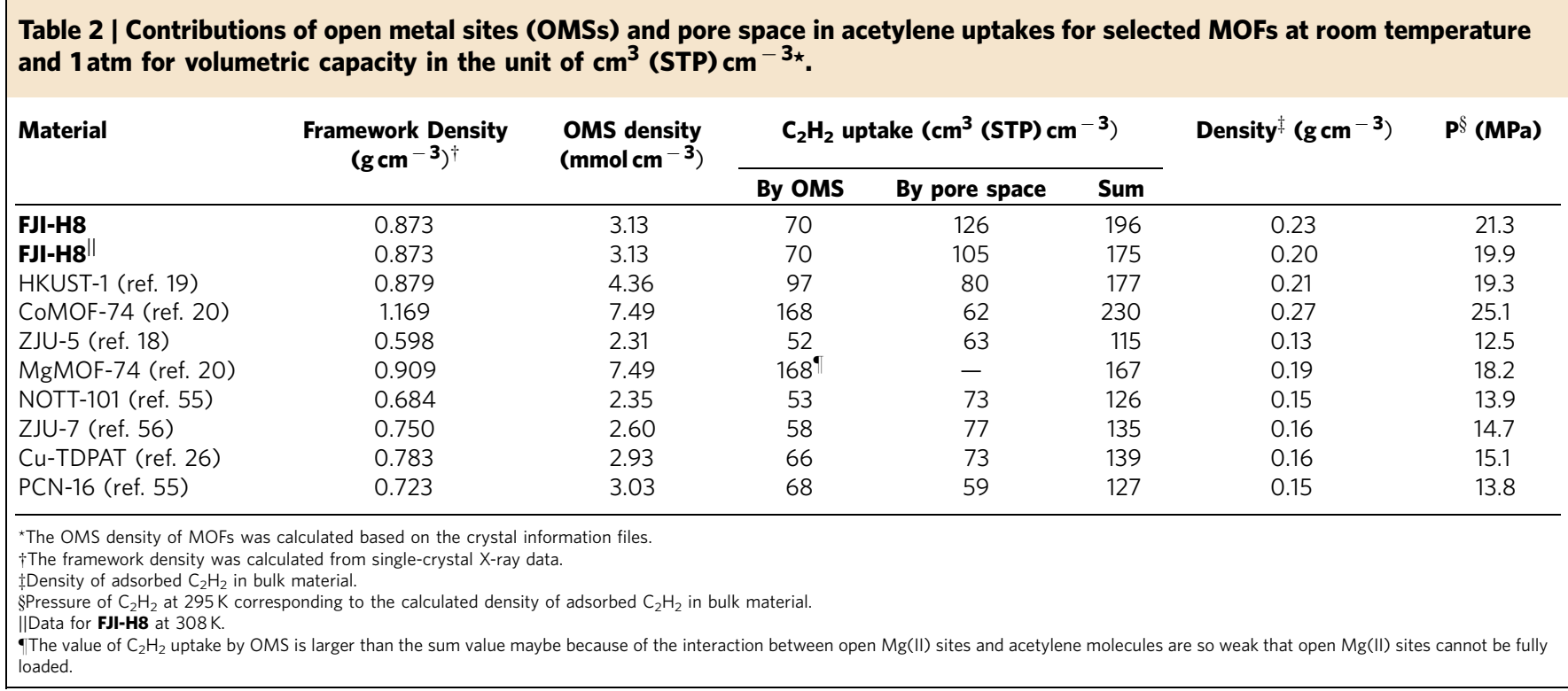

capacity in the unit of $\mathrm{cm}^{3}(\mathrm{STP}) \mathrm{cm}^{-3}$. The relationship between them is $V_{\text {volumetric }}=V_{\text {gravimetric }} \times \rho$. If we take the solvent-free crystal density into consideration, FJI-H8 shows an acetylene uptake of $196 \mathrm{~cm}^{3}(\mathrm{STP}) \mathrm{cm}^{-3}$ at $295 \mathrm{~K}$ and $1 \mathrm{~atm}$, which is only inferior to the uptake of $230 \mathrm{~cm}^{3}$ (STP) $\mathrm{cm}^{-3}$ for CoMOF-74 under the same conditions ${ }^{20}$. On the basis of the volumetric acetylene uptake, FJI-H8 shows a safe acetylene storage density of $0.23 \mathrm{~g} \mathrm{~cm}^{-3}$ in bulk material at $295 \mathrm{~K}$ and $1 \mathrm{~atm}$, which is equivalent to the value of an imaginary state of acetylene under $21.3 \mathrm{MPa}$ at room temperature and is $\sim 100$ times of the compression limit for the safe storage of acetylene $(0.2 \mathrm{MPa})$ at room temperature $3,43,44$. This value is also at the highest level for the reported MOFs, and is only slightly lower than that of CoMOF-74 $\left(0.27 \mathrm{~g} \mathrm{~cm}^{-3}\right)$, which is consistent with the volumetric analysis (Table 2 ).

Similarly, supposing each open metal site binds one acetylene molecule, the acetylene uptake by open $\mathrm{Cu}(\mathrm{II})$ sites in HKUST-1 accounts for c.a. $54 \%$ of the volumetric acetylene uptake at room temperature. For CoMOF-74, 73\% of the volumetric acetylene uptake is contributed by open $\mathrm{Co}$ (II) sites if each $\mathrm{Co}$ (II) site binds one acetylene molecule. Much like the gravimetric capacity, for the volumetric acetylene uptake of MgMOF-74 if all the open $\mathrm{Mg}$ (II) sites can be fully loaded with one acetylene molecule per each open $\mathrm{Mg}$ (II) site, the theoretical acetylene uptake by open metal sites is even larger than the experimental one at room temperature. As listed in Table 2 for most MOF materials, the volumetric acetylene uptake capacities contributed by open metal sites account for almost half of the acetylene uptakes or even higher. However, in FJI-H8, the open $\mathrm{Cu}$ (II) sites can only contribute $70 \mathrm{~cm}^{3}$ out of the total $196 \mathrm{~cm}^{3}$ volumetric acetylene storage capacity at $295 \mathrm{~K}$ and $1 \mathrm{~atm}$. Comparatively, the volumetric acetylene uptake by the suitable pore space in FJI-H8 contributed to $64 \%$ of the whole amount, which is consistent with the gravimetric analysis aforementioned.

The GCMC simulation. Theoretically, the confirmation of acetylene adsorption sites within the MOF skeletons is very important for us to design new MOFs-based gas storage materials. The most intuitive method to get the confirmation of adsorbed acetylene molecules is single-crystal diffractions or the poly-crystal power diffractions ${ }^{45,46}$. However, the above methods usually require high quality crystalline samples with high stability, which is not always available. On the other hand, theoretical simulation is a powerful tool that can give us a lot of useful information ${ }^{19,47,48}$. To understand the acetylene-framework interactions, the acetylene adsorption property of FJI-H8 was studied by grand canonical Monte Carlo (GCMC) simulations ${ }^{45-48}$. The calculated $\mathrm{C}_{2} \mathrm{H}_{2}$ adsorption isotherm is shown in Supplementary Fig. 10. As expected, the agreement between simulation and experiment of 


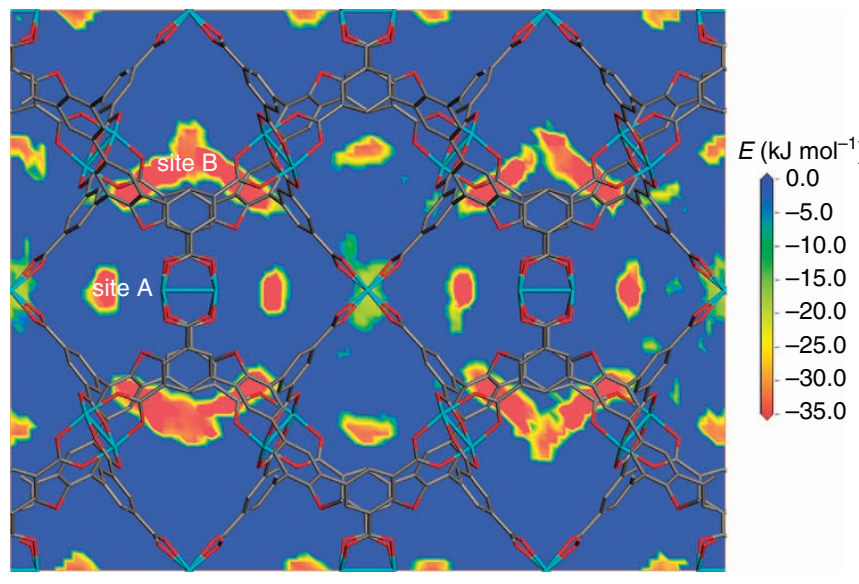

Figure 4 | Slice through the calculated potential field for acetylene in

FJI-H8. The slice is viewed along the crystallographic $a$ axis. The framework is displayed in capped sticks plot, and the hydrogen atoms are omitted for clarity.

acetylene adsorption is almost perfect at pressures below $0.3 \mathrm{~atm}$, whereas the uptake at higher pressures is slightly overestimated with a deviation of $7 \%$. Furthermore, the calculated adsorption heat of $28.7 \mathrm{~kJ} \mathrm{~mol}^{-1}$ is also comparable to the experimental one (Supplementary Fig. 11). Slice through the calculated potential field for acetylene is displayed in Fig. 4. Two preferential adsorption regions are showed in the field. As anticipated, the highest potential values are located around the unsaturated metal centres. Surprisingly, a strong increase of the interaction potential is visible in the small Cage- $\mathrm{B}$, which is surrounded by eight benzene rings. However, it is noteworthy that the adsorption behaviour in Cage-B should be attributed to the interactions between the adsorbed acetylene molecules and the surrounding benzene rings rather than the four misaligned open copper sites. The adsorption in the octahedral pore is observed at the entrance windows to this pore, which is similar to HKUST-1 (refs 19,47). Therefore, the ultrahigh acetylene uptake of FJI-H8 can be attributed to the suitable pore space together with open metal sites.

\section{Discussion}

To our knowledge, the open metal sites within MOFs materials usually play an important role in the high gas storage capacities due to the strong interactions between acetylene molecules and the metal sites. Supposing each open metal site binds one acetylene molecule, for most previously reported MOF materials the acetylene uptake by open metal sites theoretically accounts for over $60 \%$ of the whole acetylene uptake at room temperature or even higher. However, in FJI-H8, the open $\mathrm{Cu}$ (II) site density is low and the acetylene uptake by the pore space accounts for $>60 \%$ of the whole amount, which is rarely seen in other reported MOFs. As is to be expected, the acetylene uptake by the pore space accounts for $>60 \%$ of the whole amount even when the crystal density is taken into consideration (Table 2). Ideally, the perfect adsorbent materials should have both high gravimetric uptake and high volumetric capacity. In practice, very few adsorbents including MOFs can meet this requirement. For example, CoMOF-74 shows the highest volumetric acetylene uptake of $230 \mathrm{~cm}^{3}$ (STP) $\mathrm{cm}^{-3}$ at $295 \mathrm{~K}$ and $1 \mathrm{~atm}$; however, the gravimetric acetylene uptake of CoMOF-74 is only $197 \mathrm{~cm}^{3}$ (STP) $\mathrm{g}^{-1}$ (ref. 20). Similarly, although the gravimetric acetylene capacity of HKUST-1 reaches up to $201 \mathrm{~cm}^{3}$ (STP) $\mathrm{g}^{-1}$ at $295 \mathrm{~K}$ and $1 \mathrm{~atm}$, it shows a volumetric acetylene uptake of $177 \mathrm{~cm}^{3}$ (STP) $\mathrm{cm}^{-3}$ (ref. 19). In our case, compared with the reported results measured at $295 \mathrm{~K}$ and $1 \mathrm{~atm}, \mathrm{FJI}-\mathrm{H} 8$ exhibits the highest acetylene uptake of $224 \mathrm{~cm}^{3}$ (STP) $\mathrm{g}^{-1}$ in gravimetric capacity, and also shows a high value of $196 \mathrm{~cm}^{3}$ (STP) $\mathrm{cm}^{-3}$ in terms of volumetric capacity, which is only lower than that of CoMOF-74, due to its lower crystal density. More importantly, high acetylene uptakes around room temperature, low decrease rate of acetylene uptakes in the temperature range from 273 to $308 \mathrm{~K}$ and excellent repeatability make FJI-H8 a suitable candidate for practical applications. Although MOF-based acetylene storage has not exhibited economical advantage to acetone-based one at this stage, the purity of acetylene stored in FJI-H8 is higher than that in acetone. Furthermore, since acetone is an explosive pollutant, the storage of acetylene by recyclable FJI-H8 is safer and cleaner. More importantly, the cost of MOF-based acetylene storage may decrease markedly if large-scale application is implemented. Therefore, the exploration of MOFs for safe and pure acetylene storage is significant not only for theoretical studies but also for practical applications.

In conclusion, FJI-H8 is a promising candidate for acetylene storage at around room temperature. The high acetylene uptake of FJI-H8 shows that not only open metal sites but also suitable pore space plays key roles in MOF-based acetylene storage. Our results shed light on the rational design and synthesis of new MOFs materials for acetylene storage based on the two factors above.

\section{Methods}

Materials and equipment. All reagents and solvents used in synthetic studies were commercially available and used as supplied without further purification. The ligand $\mathrm{H}_{8} \mathrm{tddb}\left(\mathrm{H}_{8} \mathrm{tddb}=3,3^{\prime}, 5,5^{\prime}\right.$-tetra(3,5-dicarboxyphenyl)-4,4'-dimethoxybiphenyl) was synthesized through the routine in the Supplementary Fig. 1.

Elemental analyses for $\mathrm{C}, \mathrm{H}$ and $\mathrm{N}$ were carried out on a German Elementary Vario EL III instrument. ${ }^{1} \mathrm{H}$ NMR spectra were obtained on a Burker AVANCE $400(400 \mathrm{MHz})$ for spectrometer. Mass-accurate match spectra were obtained using a DECAX-30000 LCQ Deca XP mass spectrometer with electro-spray ionization (ESI). The PXRD patterns were collected by a Rigaku Mini 600 X-ray diffractometer using $\mathrm{Cu} K \alpha$ radiation $(\lambda=1.54 \AA)$. Simulations of the PXRD spectrum are carried out by the single-crystal data and diffraction-crystal module of the Mercury program available free of charge via internet at http://www.ccdc. cam.ac.uk/products/mercury/.

Synthesis of $3,3^{\prime}, 5,5^{\prime}$-tetrabromo-4, $4^{\prime}$-biphenol (1). Bromine $(13.8 \mathrm{ml}$ $268.6 \mathrm{mmol})$ was rapidly added to a solution of $4,4^{\prime}$-biphenol $(10 \mathrm{~g}, 54 \mathrm{~mol})$ in methanol $(400 \mathrm{ml})$. After $1 \mathrm{~h}$ of stirring, the resulting precipitate was filtered and washed sequentially with aqueous solutions of $\mathrm{NaHCO}_{3}, \mathrm{Na}_{2} \mathrm{SO}_{3}$ and water. The resulting white powder was dissolved in acetone and dried over anhydrous $\mathrm{Na}_{2} \mathrm{SO}_{4}$ Pure compound 1 was obtained by recrystallization in acetone (14.6 g, 54\%).

${ }^{1} \mathrm{H}$ NMR $\left(400 \mathrm{MHz}, \mathrm{CDCl}_{3}\right) \delta 5.93$ (s, 2H), 7.60 (s, 4H) p.p.m.

Synthesis of $3,3^{\prime}, 5,5^{\prime}$-tetrabromo-4,4'-dimethoxy-1,1'-biphenyl (2). Compound 1 (4.0 g, $8 \mathrm{mmol})$, iodomethane $(6.8 \mathrm{~g}, 48 \mathrm{mmol})$ and $\mathrm{K}_{2} \mathrm{CO}_{3}(3.3 \mathrm{~g}, 24 \mathrm{mmol})$ were dissolved into acetonitrile $(100 \mathrm{ml})$. The reaction mixture was heated at reflux for $18 \mathrm{~h}$ and then cooled to room temperature. Acetonitrile was removed using rotary evaporator and the resulting mixture was poured into water and extracted with dichloromethane $(3 \times 100 \mathrm{ml})$. The combined organic layers were dried over anhydrous $\mathrm{MgSO}_{4}$, and then the solvent was removed again using rotary evaporator. After purification by column chromatography on silica gel using hexane as eluent and evaporation of the fraction containing the product, compound 2 was obtained as a white powder. $(2.88 \mathrm{~g}, 68 \%) .{ }^{1} \mathrm{H}$ NMR $\left(400 \mathrm{MHz}, \mathrm{CDCl}_{3}\right) \delta 3.94(\mathrm{~s}, 6 \mathrm{H}), 7.65$ (s, 4H) p.p.m.

Synthesis of 3,3',5,5'-tetra(diethyl-3,5-dicarboxyphenyl)-4,4'-dimethoxy-biphenyl (3). Compound 2 (1.06 g, 2 mmol), diethyl 5-(4,4,5,5-tetramethyl-1,3,2dioxaborolan-2-yl)-1,3-benzenedicarboxylate (4.18 g, $12 \mathrm{mmol}), \mathrm{Cs}_{2} \mathrm{CO}_{3}(11.8 \mathrm{~g}$ $36 \mathrm{mmol})$ and tetrakis(triphenylphosphine)palladium $(0.092 \mathrm{~g}, 0.08 \mathrm{mmol})$ were added to a 500-ml schlenk flask charged with stir bar. The flask was pumped under vacuum and refilled with $\mathrm{N}_{2}$ for three times, and then $350 \mathrm{ml}$ degassed 1,4-dioxane was transferred to the system and the reaction mixture was heated to $85^{\circ} \mathrm{C}$ for $72 \mathrm{~h}$ under $\mathrm{N}_{2}$ atmosphere. After the reaction mixture was cooled to room temperature, the organic solvent was removed using rotary evaporator, and the resulting mixture was poured into water and extracted with dichloromethane $(3 \times 100 \mathrm{ml})$. The combined organic layers were dried over anhydrous $\mathrm{MgSO}_{4}$, and then the solvent was removed again using rotary evaporator. After purification by column chromatography on silica gel using ethyl acetate/hexane $(1: 5 \mathrm{v} / \mathrm{v})$ as eluent and evaporation of the fraction containing the product, compound 3 was obtained as a pale yellow solid. (1.60 g, 73\%). ${ }^{1} \mathrm{H}$ NMR $\left(400 \mathrm{MHz}, \mathrm{CDCl}_{3}\right): \delta 1.44(\mathrm{t}, 24 \mathrm{H})$, $3.21(\mathrm{~s}, 6 \mathrm{H}), 4.45(\mathrm{q}, 16 \mathrm{H}), 7.66(\mathrm{~s}, 4 \mathrm{H}), 8.52(\mathrm{~s}, 8 \mathrm{H}), 8.73$ (s, 4H) p.p.m. 
Synthesis of 3,3',5,5'-tetra(3,5-dicarboxyphenyl)-4,4'-dimethoxy-biphenyl $\left(H_{8} t d d b\right)$. Compound $3(2.19 \mathrm{~g}, 4 \mathrm{mmol})$ was dissolved in $20 \mathrm{ml}$ of THF, to which $20 \mathrm{ml}$ of $10 \mathrm{M} \mathrm{NaOH}$ aqueous solution was added. The mixture was stirred under reflux for $10 \mathrm{~h}$, and then the organic solvent was removed using rotary evaporator. The aqueous phase was acidified to $\mathrm{pH} 2$ using $6 \mathrm{M} \mathrm{HCl}$ aqueous solution. The resulting precipitate was collected via filtration, washed with water $(200 \mathrm{ml})$ and dried under vacuum to afford $\mathbf{H}_{\mathbf{8}}$ tddb. (1.58 g, 91\%). ${ }^{1} \mathrm{H}$ NMR $(400 \mathrm{MHz}$, DMSO$\left.d_{6}\right) \delta, 3.10(\mathrm{~s}, 6 \mathrm{H}), 7.97(\mathrm{~s}, 4 \mathrm{H}), 8.43(\mathrm{~s}, 8 \mathrm{H}), 8.51(\mathrm{~s}, 4 \mathrm{H}), 13.40(\mathrm{~s}, 8 \mathrm{H})$ p.p.m.

${ }^{13} \mathrm{C}$ NMR $\left(100 \mathrm{MHz}\right.$, DMSO- $\left.d_{6}\right) \delta, 167.0,154.5,139.0,136.4,134.5,134.4,132.0$, 130.1, 129.4, 61.1 p.p.m. ESI-MS (ESI ${ }^{-}$mode): calculated for $\mathrm{C}_{46} \mathrm{H}_{30} \mathrm{O}_{18}: 869.1$. Found: 869.0 .

Synthesis of FII-H8. $\mathrm{Cu}\left(\mathrm{NO}_{3}\right)_{2} \cdot 2 \mathrm{H}_{2} \mathrm{O}(30 \mathrm{mg})$ and $\mathrm{H}_{8} \mathrm{tddb}(10 \mathrm{mg})$ were dissolved in $1.5 \mathrm{ml}$ of $\mathrm{N}, \mathrm{N}$-diethylformamide and $0.45 \mathrm{ml}$ of water in a $25 \mathrm{ml}$ pyrex vial, to which $25 \mu \mathrm{l}$ of $\mathrm{HCl}$ were added. The mixture was heated in $85^{\circ} \mathrm{C}$ oven for $12 \mathrm{~h}$ to yield $6 \mathrm{mg}$ of blue-green crystals (yield: $46 \%$ based on $\mathrm{H}_{8} \mathrm{tddb}$ ). The crystals obtained were filtered and washed with $\mathrm{N}, \mathrm{N}$-diethylformamide. Elemental analyses calculated (\%) for $\mathrm{C}_{46} \mathrm{H}_{42} \mathrm{O}_{26} \mathrm{Cu}_{4}$. (After activation and absorbed small amount of water, the crystal has a formula of $\left.\mathrm{Cu}_{4}\left(\mathrm{H}_{2} \mathrm{O}\right)_{4}(\mathrm{tddb}) \cdot 6 \mathrm{H}_{2} \mathrm{O}\right)$ : C 42.63, H 3.26; found: C $45.82, \mathrm{H} 3.65$.)

X-ray data collection and structure determination of FJI-H8. A blue-green block crystal of FJI-H8 was taken directly from the mother liquor, transferred to oil and mounted into a loop. The crystal was kept at 100.0(1) K during data collection on a SuperNova diffractometer equipped with $\mathrm{Cu}-\mathrm{K} \alpha$ radiation $(\lambda=1.5418 \AA)$ using a $\omega$ scan mode. The crystal structure was solved by direct method and refined by full-matrix least squares on $F^{2}$ using SHELXTL package ${ }^{49}$. All non-hydrogen atoms were refined with anisotropic displacement parameters. The hydrogen atoms on the aromatic rings were located at geometrically calculated positions and refined by riding. However, the hydrogen atoms for the coordinated molecules cannot be found from the residual electron density peaks and the attempt of theoretical addition was not done. Therefore, the number of reported hydrogen atoms is more than the calculated one. The free solvent molecules are highly disordered in FJI-H8, and attempts to locate and refine the solvent peaks were unsuccessful. The diffused electron densities resulting from these solvent molecules were removed using the SQUEEZE routine of PLATON ${ }^{40}$; structures were then refined again using the data generated. Crystal data are summarized in Supplementary Table 2.

Low-pressure gas sorption measurements. Low-pressure ( $<1$ bar) adsorption measurements were performed using a Micromeritics ASAP 2020-M surface area and pore size analyser. The fresh crystalline sample of FJI-H8 was degassed under dynamic vacuum at $80^{\circ} \mathrm{C}$ for $10 \mathrm{~h}$ after solvent exchange with methanol and then dichloromethane for 3 days each. A colour change from blue-green to deep purple-blue was observed during the activation process, which is attributed to the remove of terminal coordinated water of dicopper(II) paddlewheel SBUs, thus indicating the generation of open metal sites in the framework. Low-pressure $\mathrm{N}_{2}$ adsorption isotherms were measured at $77 \mathrm{~K}$ in a liquid nitrogen bath. The specific surface areas were determined using the Brunauer-Emmett-Teller model from the $\mathrm{N}_{2}$ sorption data. Low-pressure acetylene adsorption isotherms were measured at $273,295,303$ and $308 \mathrm{~K}$. The isosteric heat of adsorption was calculated through the Clausius-Clapeyron equation using the four sets of acetylene adsorption data collected.

Computational methods. To characterize the adsorption sites of acetylene molecules in FJI-H8, GCMC simulations were carried out using Sorption Module in Materials Studio ${ }^{50}$. The FJI-H8 framework was fixed at the crystallographic data based on the single-crystal X-ray diffraction. Four unit cells of FJI-H8 $(2 \times 2 \times 1)$ were used to construct the simulation box of the GCMC run. Then, the structural parameters of simulation box are $a=b=35.8514 \AA$ and $c=28.0627 \AA$, as well as $\alpha=\beta=\gamma=90$.

DFT calculations. Density functional theory (DFT) calculations were performed to derive the charges to be used in the GCMC simulations to estimate the adsorption isotherms of acetylene in FJI-H8. The atomic coordinates were taken from the experimental crystallographic data. The cluster included building units (for example, metal ion nodes and the organic linker) representative of the unit cells. Details of structure and atom types of the FJI-H8 clusters are shown in Supplementary Fig. 12. The DFT calculations were performed with the Gaussian 09 (ref. 51) software at the B3LYP/6-31G*

level of theory. Partial atomic charges were extracted using the ChelpG method ${ }^{52}$ by fitting them to reproduce the electrostatic potential generated by the DFT calculations. The charge of $\mathrm{Cu}$ was slightly adjusted to result in a neutral framework. Resulting partial charges for FJI-H8 are given in Supplementary Table 3.

Acetylene model. The model of acetylene molecule was taken from the literature $^{47}$. In this model, the acetylene molecule is a rigid structure where the $\mathrm{C}-\mathrm{C}$ and $\mathrm{C}-\mathrm{H}$ bond lengths are fixed at 1.2111 and $1.0712 \AA$, respectively (Supplementary Fig. 13). To account for the electrostatic interaction, point charges of $0.2780 e$ were assigned to $\mathrm{H}$ and $\mathrm{C}$ atoms of acetylene molecule, which were derived from DFT calculations using the ESP methods. Supplementary Table 4 shows bond lengths, ESP charge $q$ and quadrupole moment $\theta$ for acetylene.
To represent van der Waals interactions, the acetylene molecule was treated as a two-site model, in which $\mathrm{H}$ atoms in acetylene molecule were represented as non-interacting atoms and the Lennard-Jones (LJ) positions located on the carbon atoms. The LJ parameters for $s p$-hybridized carbon was taken from the central $\mathrm{CH}$ groups of 2-butene in the literature ${ }^{53}$.

Force-field parameters. LJ parameters for FJI-H8 atoms were taken from the Universal force field ${ }^{54}$. LJ parameters for acetylene and LJ parameters representing the interaction of the acetylene molecules with the copper centres of FJI-H8 were taken from the literature ${ }^{47}$. Supplementary Table 5 shows the LJ parameters for all atom types found in FJI-H8 and acetylene.

GCMC simulation. These simulations were performed with the Sorption module of Materials Studio50. All GCMC simulations included a 4,000,000-cycle equilibration period followed by a 4,000,000-cycle production run. Atoms in FJI-H8 were held fixed at their crystallographic positions. The van der Waals interactions were represented using a LJ potential, applying Lorentz-Berthelot mixing rules to calculate interactions between different atom types. An LJ cutoff distance of $12.5 \AA$ was used for the simulations. The Ewald sum technique was used to compute the electrostatic interactions. Four unit cells of FJI-H8 were used for the simulations. Acetylene isotherms were simulated at $295 \mathrm{~K}$ up to $1.0 \mathrm{bar}$ GCMC simulations reported the absolute adsorption data, which were then used to compute the excess adsorption data for comparison with experimental data using the relation

$$
N_{\text {excess }}=N_{\text {total }}-V_{\mathrm{p}} \times \rho,
$$

where $\rho$ is the bulk density of acetylene at simulation conditions. The density needed was calculated using the Peng-Robinson equation of state. $V_{\mathrm{p}}$ is the pore volume calculated by PLATON ${ }^{40}$.

\section{References}

1. Stang, P. J. \& Diederich, F. Modern Acetylene Chemistry (Wliey-VCH, 1995).

2. Chien, J. C. W. Polyacetylene Chemistry, Physics, and Material Science (Academic, 1984).

3. Matsuda, R. et al. Highly controlled acetylene accommodation in a metal-organic microporous material. Nature 436, 238-241 (2005).

4. Budavari, S. The merck Index. 12th edn (Merck Research Laboratories, 1996).

5. Getman, R. B., Bae, Y. S., Wilmer, C. E. \& Snurr, R. Q. Review and analysis of molecular simulations of methane, hydrogen, and acetylene storage in metal-organic frameworks. Chem. Rev. 112, 703-723 (2012).

6. He, Y.-B., Zhou, W., Qian, G.-D. \& Chen, B.-L. Methane storage in metal-organic frameworks. Chem. Soc. Rev. 43, 5657-5678 (2014).

7. Furukawa, H., Cordova, K. E., O’Keeffe, M. \& Yaghi, O. M. The chemistry and applications of metal-organic frameworks. Science 341, 1230444 (2013).

8. Mason, J. A., Veenstra, M. \& Long, J. R. Evaluating metal-organic frameworks for natural gas storage. Chem. Sci. 5, 32-51 (2014).

9. Wilmer, C. E. et al. Gram-scale, high-yield synthesis of a robust metal-organic framework for storing methane and other gases. Energy Environ. Sci. 6, 1158-1163 (2013).

10. Huck, J. M. et al. Evaluating different classes of porous materials for carbon capture. Energy Environ. Sci. 7, 4132-4146 (2014).

11. Zhang, Z.-J., Yao, Z.-Z., Xiang, S.-C. \& Chen, B.-L. Perspective of microporous metal-organic frameworks for $\mathrm{CO}_{2}$ capture and separation. Energy Environ. Sci. 7, 2868-2899 (2014).

12. Murray, L.-J., Dinca, M. \& Long, J. R. Hydrogen storage in metal-organic frameworks. Chem. Soc. Rev. 38, 1294-1314 (2009)

13. Suh, M. P., Park, H. J., Prasad, T. K. \& Lim, D. W. Hydrogen storage in metal-organic frameworks. Chem. Rev. 112, 782-835 (2012).

14. Zhuang, W.-J. et al. Robust metal-organic framework with an octatopic ligand for gas adsorption and separation: combined characterization by experiments and molecular simulation. Chem. Mater. 24, 18-25 (2012).

15. Peng, Y. et al. Methane storage in metal-organic framework: current records, surprise findings, and challenges. J. Am. Chem. Soc. 135, 11887-11894 (2013)

16. Decoste, J. B. et al. Metal-organic frameworks for oxygen storage. Angew. Chem. Int. Ed. 53, 14092-14095 (2014).

17. Barin, G. et al. Isoreticular series of $(3,24)$-connected metal-organic frameworks: facile synthesis and high methane uptake properties. Chem. Mater. 26, 1912-1917 (2014).

18. Rao, X.-T. et al. A microporous metal-organic framework with both open metal and Lewis basic pyridyl sites for high $\mathrm{C}_{2} \mathrm{H}_{2}$ and $\mathrm{CH}_{4}$ storage at room temperature. Chem. Commun. 49, 6719-6721 (2013).

19. Xiang, S.-C., Zhou, W., Gallegos, J. M., Liu, Y. \& Chen, B.-L. Exceptionally high acetylene uptake in a microporous metal-organic framework with open metal sites. J. Am. Chem. Soc. 131, 12415-12419 (2009).

20. Xiang, S.-C. et al. Open metal sites within isostructural metal-organic frameworks for differential recognition of acetylene and extraordinarily high acetylene storage capacity at room temperature. Angew. Chem. Int. Ed. 49, 4615-4618 (2010).

21. $\mathrm{Xu}, \mathrm{H}$. et al. A microporous metal-organic framework with both open metal and Lewis basic pyridyl sites for highly selective $\mathrm{C}_{2} \mathrm{H}_{2} / \mathrm{CH}_{4}$ and $\mathrm{C}_{2} \mathrm{H}_{2} / \mathrm{CO}_{2}$ gas separation at room temperature. J. Mater. Chem. A 1, 77-81 (2013). 
22. Xu, H. et al. A cationic microporous metal-organic framework for highly selective separation of small hydrocarbons at room temperature. J. Mater. Chem. A 1, 9916-9921 (2013).

23. Samsonenko, D. G. et al. Microporous magnesium and manganese formates for acetylene storage and separation. Chem. Asian J. 2, 484-488 (2007).

24. Zhang, J.-P. \& Chen, X.-M. Optimized acetylene/carbon dioxide sorption in a dynamic porous crystal. J. Am. Chem. Soc. 131, 5516-5521 (2009).

25. Yang, S. et al. Supramolecular binding and separation of hydrocarbons within a functionalized porous metal-organic framework. Nat. Chem. 7, 121-129 (2015).

26. Liu, K. et al. High storage capacity and separation selectivity for $\mathrm{C}_{2}$ hydrocarbons over methane in the metal-organic framework $\mathrm{Cu}$-TDPAT. J. Mater. Chem. A 2, 15823-15828 (2014).

27. Xue, Y.-S. et al. A robust microporous metal-organic framework constructed from a flexible organic linker for acetylene storage at ambient temperature. J. Mater. Chem. 22, 10195-10199 (2012).

28. Ma, L.-Q., Mihalcik, D. J. \& Lin, W.-B. Highly porous and robust 4,8-connected metal-organic frameworks for hydrogen storage. J. Am. Chem. Soc. 131, 4610-4612 (2009).

29. Yuan, D.-Q., Zhao, D., Sun, D.-F. \& Zhou, H.-C. An isoreticular series of metal-organic frameworks with dendritic hexacarboxylate ligands and exceptionally high gas-uptake capacity. Angew. Chem. Int. Ed. 49, 5357-5361 (2010).

30. Pang, J.-D. et al. Coexistence of cages and one-dimensional channels in a porous MOF with high $\mathrm{H}_{2}$ and $\mathrm{CH}_{4}$ uptakes. Chem. Commun. 50, 2834-2836 (2014).

31. He, Y.-B., Li, B., O’Keeffe, M. \& Chen, B.-L. Multifunctional metal-organic frameworks constructed from meta-benzenedicarboxylate units. Chem. Soc Rev. 43, 5618-5656 (2014).

32. Yan, Y., Yang, S., Blake, A. J. \& Schroder, M. Studies on metal-organic frameworks of $\mathrm{Cu}$ (II) with isophthalate linkers for hydrogen storage. Acc. Chem. Res. 47, 296-307 (2014).

33. Farha, O. K. et al. De novo synthesis of a metal-organic framework material featuring ultrahigh surface area and gas storage capacities. Nat. Chem. 2 944-948 (2010).

34. Lu, W.-G., Yuan, D.-Q., Makal, T. A., Li, J.-R. \& Zhou, H.-C. A highly porous and robust $(3,3,4)$-connected metal-organic framework assembled with a 90 degrees bridging-angle embedded octacarboxylate ligand. Angew. Chem. Int. Ed. 51, 1580-1584 (2012).

35. Wang, X.-S. et al. Enhancing $\mathrm{H}_{2}$ uptake by "close-packing" alignment of open copper sites in metal-organic frameworks. Angew. Chem. Int. Ed. 47, 7263-7266 (2008).

36. Ma, S.-Q., Simmons, J. M., Sun, D.-F., Yuan, D.-Q. \& Zhou, H.-C. Porous metalorganic frameworks based on an anthracene derivative: syntheses, structure analysis, and hydrogen sorption studies. Inorg. Chem. 48, 5263-5268 (2009).

37. Ma, S.-Q. et al. Metal-organic framework from an anthracene derivative containing nanoscopic cages exhibiting high methane uptake. J. Am. Chem. Soc. 130, 1012-1016 (2008).

38. Li, J.-R. et al. Porous materials with pre-designed single-molecule traps for $\mathrm{CO}_{2}$ selective adsorption. Nat. Commun. 4, 1538 (2013).

39. Blatov, V. A., Shevchenko, A. P. \& Proserpio, D. M. Applied topological analysis of crystal structures with the program package toposPro. Cryst. Growth Des. 14, 3576-3586 (2014).

40. Spek, A. L. Single-crystal structure validation with the program PLATON. J. Appl. Cryst. 36, 7-13 (2003).

41. Sarkisov, L. \& Harrison, A. Computational structure characterisation tools in application to ordered and disordered porous materials. Mol. Simul. 37, 1248-1257 (2011).

42. Qian, J.-J. et al. Unusual pore structure and sorption behaviour in a hexanodal zinc-organic framework material. Chem. Commun. 50, 1678-1681 (2014).

43. He, Y.-B., Zhou, W., Krishna, R. \& Chen, B.-L. Microporous metal-organic frameworks for storage and separation of small hydrocarbons. Chem. Commun. 48, 11813-11831 (2012).

44. Chen, B.-L. Acetylene storage using metal-organic frameworks of the formula $\mathrm{M}_{2}$ (2,5-dihydroxyterephthalate). US 8,664,419 B2 (2014).

45. Kubota, Y. et al. Metastable sorption state of a metal-organic porous material determined by in situ synchrotron powder diffraction. Angew. Chem. Int. Ed. 45, 4932-4936 (2006).
46. Jang, S. B., Jeong, M. S. \& Kim, Y. Crystal structure of an acetylene sorption complex of dehydrated fully $\mathrm{Cd}^{2+}$-exchanged zeolite X. Zeolites 19, 228-237 (1997).

47. Fischer, M., Hoffmann, F. \& Froba, M. New microporous materials for acetylene storage and $\mathrm{C}_{2} \mathrm{H}_{2} / \mathrm{CO}_{2}$ separation: insights from molecular simulations. ChemPhysChem 11, 2220-2229 (2010).

48. Guo, H.-C., Shi, F., Ma, Z.-F. \& Liu, X.-Q. Simulation of separation of $\mathrm{C}_{2} \mathrm{H}_{6}$ from $\mathrm{CH}_{4}$ using zeolitic imidazolate frameworks. Mol. Simul. 40, 349-360 (2013).

49. Sheldrick, G. M. A short history of SHELX. Acta Cryst. A 64, 112-122 (2008) 50. Accelrys Materials Studio, version 6.0 (Accelrys Inc, San Diego, USA, 2012).

51. Frisch, M. J. et al. GAUSSIAN 09 Program (Gaussian Inc., 2009).

52. Breneman, C. M. \& Wiberg, K. B. Determining atom-centered monopoles from molecular electrostatic potentials - the need for high sampling density in formamide conformational-analysis. J. Comput. Chem. 11, 361-373 (1990).

53. Jorgensen, W. L., Madura, J. D. \& Swenson, C. J. Optimized intermolecular potential functions for liquid hydrocarbons. J. Am. Chem. Soc. 106, 6638-6646 (1984).

54. Rappe, A. K., Casewit, C. J., Colwell, K. S., Goddard, W. A. \& Skiff, W. M. UFF, a full periodic table force field for molecular mechanics and molecular dynamics simulations. J. Am. Chem. Soc. 114, 10024-10035 (1992).

55. He, Y.-B., Krishna, R. \& Chen, B.-L. Metal-organic frameworks with potential for energy-efficient adsorptive separation of light hydrocarbons. Energy Environ. Sci. 5, 9107-9120 (2012).

56. Cai, J.-F. et al. A NbO type microporous metal-organic framework constructed from a naphthalene derived ligand for $\mathrm{CH}_{4}$ and $\mathrm{C}_{2} \mathrm{H}_{2}$ storage at room temperature. RSC Adv. 4, 49457-49461 (2014).

\section{Acknowledgements}

This work was financially supported by the 973 Program (2011CBA00507 and 2011CB932504), National Nature Science Foundation of China (21131006, 21271172 and 21371169). W.L. acknowledges the Laboratory for Molecular Simulation of Texas A\&M University for providing the Material Studio software.

\section{Author contributions}

D.Y., M.W., F.J. and M.H. conceived and designed the experiments and co-wrote the paper. J.P. performed most of experiments and analysed the data. C.L. and W.L. worked on all computational simulations. K.S. performed ligand synthesis. D.Y., M.W. and J.P analysed the data and wrote the manuscript. All authors discussed the results and commented on the manuscript.

\section{Additional information}

Accession codes: The X-ray crystallographic coordinates for structure reported in this Article have been deposited at the Cambridge Crystallographic Data Centre (CCDC), under deposition number CCDC 1048132. These data can be obtained free of charge from The Cambridge Crystallographic Data Centre via www.ccdc.cam.ac.uk/data request/cif.

Supplementary Information accompanies this paper at http://www.nature.com/ naturecommunications

Competing financial interests: The authors declare no competing financial interests.

Reprints and permission information is available online at http://npg.nature.com/ reprintsandpermissions/

How to cite this article: Pang, J. et al. A porous metal-organic framework with ultrahigh acetylene uptake capacity under ambient conditions. Nat. Commun. 6:7575 doi: $10.1038 /$ ncomms8575 (2015)

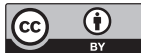

This work is licensed under a Creative Commons Attribution 4.0 International License. The images or other third party material in this article are included in the article's Creative Commons license, unless indicated otherwise in the credit line; if the material is not included under the Creative Commons license, users will need to obtain permission from the license holder to reproduce the material. To view a copy of this license, visit http://creativecommons.org/licenses/by/4.0/ 